\title{
REVIEW
}

\section{COVID-19: Implications for People with Chagas Disease}

\author{
Ezequiel José Zaidel ${ }^{1,2}$, Colin J. Forsyth ${ }^{3}$, Gabriel Novick ${ }^{4,5}$, Rachel Marcus ${ }^{6}$, \\ Antonio Luiz P. Ribeiro7,8, María-Jesus Pinazo9, Carlos A. Morillo ${ }^{10}$, \\ Luis Eduardo Echeverría ${ }^{11}$, Maria Aparecida Shikanai-Yasuda ${ }^{12}$, Pierre Buekens ${ }^{13}$, \\ Pablo Perel ${ }^{14,15}$, Sheba K. Meymandi ${ }^{16}$, Kate Ralston ${ }^{14}$, Fausto Pinto ${ }^{14,17}$ and \\ Sergio Sosa-Estani 3,18 \\ Sanatorio Güemes, Buenos Aires, AR \\ Pharmacology Department, School of Medicine, University of Buenos Aires, AR \\ Drugs for Neglected Diseases initiative-Latin America, Rio de Janeiro, BR \\ Swiss Medical Group, Buenos Aires, AR \\ Friedman School of Nutrition Science and Policy, Tufts University, Boston, US \\ Latin American Society of Chagas, Washington, DC, US \\ Internal Medicine Department, School of Medicine, Federal University of Minas Gerais (UFMG), Belo Horizonte, BR \\ Hospital das Clínicas, UFMG, Belo Horizonte, BR \\ ISGlobal, Hospital Clínic - University of Barcelona, Barcelona, ES \\ 10 Libin Cardiovascular Institute, University of Calgary, Calgary, CA \\ 11 Department of Cardiology, Cardiovascular Foundation of Colombia, Floriblanca, CO \\ 12 Department of Infectious and Parasitic Diseases, School of Medicine, University of São Paulo, São Paulo, BR \\ 13 Tulane University School of Public Health and Tropical Medicine, New Orleans, US \\ 14 World Heart Federation, Geneva, $\mathrm{CH}$ \\ 15 Department of Non-communicable Disease Epidemiology, London School of Hygiene and Tropical Medicine, London, UK \\ 16 Center of Excellence for Chagas Disease at Olive View-UCLA Medical Center, Sylmar, US \\ 17 Department of Cardiology, CCUL, Lisbon School of Medicine, Universidade de Lisboa, PT \\ 18 Epidemiology and Public Health Research Center, (CIESP-CONICET), Buenos Aires, AR \\ Corresponding author: Colin J. Forsyth (cforsyth@dndi.org)
}

As the global COVID-19 pandemic advances, it increasingly impacts those vulnerable populations who already bear a heavy burden of neglected tropical disease. Chagas disease (CD), a neglected parasitic infection, is of particular concern because of its potential to cause cardiac, gastrointestinal, and other complications which could increase susceptibility to COVID-19. The over one million people worldwide with chronic Chagas cardiomyopathy require special consideration because of COVID-19's potential impact on the heart, yet the pandemic also affects treatment provision to people with acute or chronic indeterminate CD. In this document, a follow-up to the WHF-IASC Roadmap on CD, we assess the implications of coinfection with SARS-CoV-2 and Trypanosoma cruzi, the etiological agent of CD. Based on the limited evidence available, we provide preliminary guidance for testing, treatment, and management of patients affected by both diseases, while highlighting emerging healthcare access challenges and future research needs.

Keywords: COVID-19; Chagas Disease; Neglected Tropical Disease

\section{Introduction}

In 2020, the SARS-CoV-2 virus, which causes COVID-19, took the world by storm. The biological and social implications of this global pandemic may not be fully understood for years. However, what is increasingly clear is that like other diseases, COVID-19 disproportionately affects those living at the social margins, while 
also being particularly severe in older individuals and those with certain underlying health conditions. These are both key considerations as COVID-19 increasingly intersects with the world's neglected diseases, including Chagas disease (CD), a multi-systemic disorder caused by Trypanosoma cruzi (T. cruzi) that can affect the cardiovascular, digestive and central nervous systems [1]. CD is endemic in much of Latin America, which is increasingly bearing the brunt of the pandemic. The first reported Latin American case of COVID-19 was on February 26, 2020 in Brazil; by September 4th, there were over 7.5 million confirmed infections and over 280,000 deaths in the region [2], with numbers still increasing rapidly at the time of writing this paper. Several aspects of $C D$ are of particular concern in light of what we know about COVID-19: Many people living with $\mathrm{CD}$ are socioeconomically vulnerable and have limited access to healthcare, the vast majority are undiagnosed, most are aging, and over a million have already progressed to a cardiac form of the disease $[3,4]$. This paper will focus on the potential interactions between CD and COVID-19 in coinfected individuals, which become increasingly important as the pandemic spreads rapidly through Latin American countries where $\mathrm{CD}$ is endemic.

On March 30, 2020 the Inter-American Society of Cardiology and the World Heart Federation published a roadmap that provides a comprehensive overview of $\mathrm{CD}$, with steps for improving healthcare access [5]. Also in March of 2020, the Chagas Coalition prepared a question and answer document with information about COVID-19 for people with CD. ${ }^{1}$ In April 2020, the Drugs for Neglected Diseases initiative's Chagas Research Platform reconvened some members from the roadmap writing group as well as other experts, including several members of the Chagas Coalition, to write a follow-up paper exploring how COVID-19 might impact people living with $\mathrm{CD}$, and to provide preliminary guidance based on the limited amount of evidence available on the topic. The group consisted of several CD experts, some of whom have been on the front lines during the current crisis treating patients with COVID-19 or performing research on new treatments. The following document summarizes the consensus opinion of these experts on SARS-CoV-2/T. cruzi coinfection.

\section{Pathophysiology of COVID-19 Infection in Relation to that of CD}

$\mathrm{CD}$ is mainly transmitted through various species of hematophagous insects, although it can also be transmitted transplacentally, through infected blood transfusions or organ donations, laboratory accidents, needle sharing among intravenous drug users (IVDU), and orally through food and drink contaminated with triatomines, their feces, or secretions from some host reservoir species. After infection and an incubation period of between 15 and 40 days, the acute phase of the disease generally lasts for one to two months and is followed by an indeterminate phase, when no clinical manifestations are observed. After decades in this silent state, roughly one-third of patients develop a chronic form of the disease characterized by organ damage, mainly to the cardiovascular (CV) and gastrointestinal (GI) systems. The most serious sequelae of CD are stroke, sudden death from brady- or tachyarrhythmias, and congestive heart failure [1, 6].

COVID-19 interacts with the CV system on multiple levels. SARS-CoV-2 binds to the human angiotensin-converting enzyme 2 (ACE2) receptor mainly expressed in the lungs, heart, and vascular endothelium. Although analysis of the precise consequences is in its infancy, this interaction may trigger an inflammatory response that, in turn, may lead to increasing myocardial injury and dysfunction $[7,8]$. It is uncertain whether the altered immune state characteristic of COVID-19 disease can act as a potential trigger for CD progression, and how this might be influenced by both certain parasitic factors (type of strains, load of parasites) as well as host factors (genetic susceptibility and immune state, specifically IFN- $\gamma$ axis).

While parasitemia is low-level and evanescent in chronic CD, pharmacologic and disease-induced immunosuppression risk reactivation of parasitemia [9, 10]; therefore, there is a concern that COVID-19 disease could potentially trigger reactivation of $\mathrm{CD}$. This potential reactivation could be caused by an acquired hemophagocytic lymphohistiocytosis-like disease (cytokine storm), the virus itself, or even the use of some COVID-19 treatments such as steroids, hydroxychloroquine [5] and other immune-modulating drugs (i.e. tocilizumab or other interleukin inhibitors), as interleukins are related to the progression of $C D[11,12]$. This may be influenced by certain parasitic factors or host factors.

\section{Implications for chronic Chagas cardiomyopathy}

The pathogenesis of chronic Chagas cardiomyopathy (CCC) involves a complex interaction between different processes related to tissue damage due to parasite persistence, inflammation, specific immune response, fibrosis, dysautonomia, and microvascular changes [13]. Chronic, persistent infection of the

\footnotetext{
${ }^{1}$ http://www.coalicionchagas.org/en_GB/news-article/-/asset_publisher/hJnt8AyJM2Af/content/preguntas-y-respuestas-sobrecovid-19-y-chagas).
} 
myocardium elicits an inflammatory response which, although necessary for the control of parasite proliferation, results in tissue damage leading to myocardial fibrosis and cardiac remodeling [14]. The pro-inflammatory response includes, but is not limited to, secretion of Th1 cytokines and chemokines, eicosanoids, and endothelin-1 [14].

Similar to the case for T. cruzi infection, direct damage to cardiac tissue also is possible with SARS-CoV-2, which binds to the ACE2 receptor to enter type 2 pneumocytes, macrophages, perivascular pericytes, and cardiomyocytes. This may lead to myocardial dysfunction and damage, endothelial dysfunction, microvascular dysfunction, plaque instability, and myocardial infarction (MI) [15]. Initial immune and inflammatory responses induce a severe cytokine storm [16], including cytokines and chemokines frequently related to the inflammatory response implicated in the pathogenesis of CCC, such as interleukin (IL)-6, TNF-alpha, and CXCL10 [17, 18]. Indeed, COVID-19 related myocarditis cases have been reported and are thought to be a combination of direct viral injury and cardiac damage due to the host immune response [19].

Further depression of the ventricular function by COVID-19 could be caused by additional mechanisms, such as myocardial infarction and microvascular dysfunction, also found in $T$. cruzi infection [15]. Furthermore, arrhythmia is recognized as one of the possible clinical manifestations of COVID-19 patients, thus COVID-19 could plausibly precipitate arrhythmias in patients with an arrhythmogenic substrate, such as CCC [19].

Finally, COVID-19 may predispose patients to thrombotic disease, both in the venous and arterial circulations, due to excessive inflammation, platelet activation, endothelial dysfunction, and stasis [20]. There are reports of upregulated procoagulative activity in the plasma of chronic CD patients [21] and thromboembolic manifestations are also more frequent in these patients with CCC [22], although it is not clear if this interaction has clinical relevance.

\section{Implications for chronic indeterminate $C D$}

While patients living with the indeterminate form of $\mathrm{CD}$ are usually outpatients without manifest symptoms, they still require ongoing surveillance and care, which has become increasingly difficult due to the pandemic. For instance, patients with chronic indeterminate $\mathrm{CD}$ need yearly follow-up for cardiac tests, as $2-5 \%$ progress to chronic symptomatic disease annually, and ultimately $30-40 \%$ develop cardiac or GI complications [1]. They may also benefit from antiparasitic treatment, which, in the case of women of childbearing age, can interrupt congenital transmission $[23,24]$. However, the 2-month course of treatment requires ongoing monitoring and laboratory testing due to the potential for side effects. This essential care for patients with chronic indeterminate $\mathrm{CD}$ is likely to be hampered by the pandemic, both because of the potential risk of SARS-CoV-2 infection from attending healthcare facilities for routine appointments (or the need to use public transportation to travel to and from appointments), and because of postponements or delays in routine care as healthcare personnel and resources are focused on COVID-19 cases.

Furthermore, if assessed with more sensitive technology, including echocardiography, Holter, and magnetic resonance with late gadolinium enhancement, a small number of indeterminate-phase patients may be reclassified as having CCC due to the presence of areas of fibrosis with wall motion abnormalities [25-30]. Therefore, an unknown proportion of individuals classified as being in the indeterminate phase may indeed develop arrhythmias or other cardiovascular complications if challenged with a cytokine storm such as that triggered by COVID-19.

\section{Implications for gastrointestinal and neurological forms of $C D$}

Atypical chest pain, abdominal pain, and nausea are nonspecific symptoms related to upper digestive CD involvement, and all three have been related to COVID-19 pulmonary and extrapulmonary clinical presentation [31,32]. However, constipation is the main symptom of lower digestive tract involvement due to $T$. cruzi infection which is the opposite of diarrhea, the main GI symptom observed in extrapulmonary forms of COVID-19. The presence of GI symptoms, widely described in COVID-19 case series and present in $3-11.6 \%$ of patients with COVID-19 [31], has been associated with high ACE2 expression in the GI tract that could indicate the potential of virus mutation towards increased transmissibility, decreased virulence, and multiorgan infection [31]. When GI symptoms that occur in both diseases are noted in an individual in an area of high SARS-CoV-2 transmission, etiological consideration must be given to either $\mathrm{CD}$ progression or COVID-19, considering the implications in terms of mutation and transmissibility.

There is increasing evidence that coronaviruses are associated with neurological disorders [33]. Studies on severe acute respiratory syndrome (SARS) and the Middle East respiratory syndrome (MERS) suggest that coronaviruses are neurotropic. A systematic review of the literature until April 2020 associated multiple neurological disorders with COVID-19, including encephalitis, demyelination, and neuropathy [34]. 
COVID-19 could potentially induce the development of chagasic neuropathy, which is sometimes observed in chronic $\mathrm{CD}$.

\section{Congenital cases}

Maternal-fetal transmission of $T$. cruzi occurs in an average of $5 \%$ of pregnancies of mothers with chronic CD [35]. Parasite load is a key determinant of congenital transmission [36]. The immunological response to COVID-19 is extensive, and its impact on T. cruzi parasitic load is unknown. Should it be found that COVID-19 increased parasitemia in pregnant women with CD, it could increase the likelihood of maternal-fetal transmission. Screening of infants born to T. cruzi-infected mothers remains crucial and could potentially be disrupted by the negative impact of COVID-19 on access to care [37, 38].

\section{Immunosuppressed patients}

Immunosuppressed patients are at increased risk of severe COVID-19, especially those with aggressive underlying disease, active immunosuppressive treatment, or lymphopenia. Overproduction of cytokines during COVID-19 infection leads to significant tissular damage, particularly in the lungs. This intense COVID19 inflammatory process in immunosuppressed CD patients could influence the evolution of disease and potentially trigger $C D$ reactivation, due either to viral infection interference, such as seen in HIV infection [39], or to possible immunosuppressive therapy for COVID-19 [9, 10] and is associated with the severity of underlying diseases. Conversely, any approach that improves the immune response at this level is desirable, either using antiviral or cytokine blocking agents (IL-6, IL-1 $\beta$, TNF-a) [40]. On the other hand, there is the risk of inducing clinical activation of autoimmune disease in individuals with asymptomatic COVID-19 and, consequently, a potential reactivation of $\mathrm{CD}[41]$.

\section{Epidemiological Considerations}

The spread of the COVID-19 pandemic in countries affected by CD raises concerns for several reasons. The population with $T$. cruzi infection, which numbers over six million people worldwide [3,42], is aging, at risk of CCC, has a significant burden of comorbidities, and is socioeconomically vulnerable. All these factors could potentially increase the impact of COVID-19 in this population, especially within a scenario of weakened and overloaded health systems.

In most countries where $\mathrm{CD}$ transmission has been controlled or reduced, $\mathrm{CD}$ patients are becoming older and suffer from comorbid conditions [43]. Further investigation is needed to fully understand the impact of comorbid illnesses in $\mathrm{CD}$ patients, including the role of immunosuppressive conditions arising from $\mathrm{CD}$ or from $\mathrm{CD}$ therapies. In addition to age, many chronic medical conditions, such as diabetes, COPD and other cardiovascular diseases are also known risk factors for COVID-19 mortality. Moreover, elderly CCC patients have higher risk of death than age-matched seronegative individuals [43]. It is likely, therefore, that CCC, in part because of its association with age and other chronic conditions, along with the challenging socioeconomic context affecting many people with CD, would further increase the risks of severe COVID-19 infection.

Although the incidence of new CD infections is around 30,000 annually [3], this number has declined in recent decades, meaning a high proportion of people living with $\mathrm{CD}$ are older or aging [44]. While $>80 \%$ of COVID-19 cases are mild or asymptomatic, severe cases are more common among older adults. In a retrospective study, the risk of mortality increased by $1.03-1.17 \%$ with every year of increased age in patients from Wuhan [45]. Another study using data from various countries estimated a case fatality ratio of $4.5 \%$ in individuals older than 60 , compared to $1.4 \%$ in those younger than 60 , with the highest rates in patients over 80 [46]. In the United States, 78.6\% of deaths have occurred in people 65 or older [47].

Over one million people in the Americas suffer from CCC [3], and underlying cardiovascular disease is a major risk factor for hospitalization and death from COVID-19. The incidence of acute cardiac injury from COVID-19 has been reported as $8 \%$ in hospitalized patients (48), and (in one Chinese study) was much more prevalent in deceased (59\%) than recovering patients (1\%) [49]. Cardiovascular disease was also identified in 30\% of COVID-19 related deaths in Italy [50], while age $>60$ and Charlson Comorbidity Index $>3$ were associated with greater mortality in a U.S. cohort of 1305 hospitalized patients [51].

Finally, several studies have noted high levels of comorbidities among both patients with $C D$ and those with severe forms of COVID-19. One Brazilian study identified a mean of 2.7 chronic comorbidities in CD patients [52]. In $168 \mathrm{CD}$ patients in São Paulo, 51.2\% had hypertension and 23.8\% had diabetes mellitus [53]. Another study in a younger sample of 137 patients in Switzerland found $2.9 \%$ had diabetes and $17 \%$ had hypertension [54]. Both hypertension and diabetes were associated with high mortality rates from COVID-19 in China (7.3\% and 6.0\% respectively) [55], and were 2-3 times more prevalent in severe vs. 
non-severe hospitalizations [48]. Diabetes was also prevalent in a third of deaths in an analysis of Italian COVID-19 data [56]. It is important to note that these comorbidities also reflect the older age of the populations which are especially impacted by both CD and COVID- 19 .

\section{Social Context and Access to Healthcare}

As the pandemic progresses from Europe and the United States into the Global South, it is increasingly impacting vulnerable populations. In the U.S., COVID-19 has thus far had a greater impact on Blacks and Latinos. According to the $\mathrm{CDC}$, these groups have a higher prevalence of infection and higher weighted distribution of deaths than expected from their distribution in the general population [57]. A higher rate of deaths among people in Brazil who self-identify as black has also been reported [58, 59]. These racial disparities are, in turn, framed by historically rooted socioeconomic considerations which often determine who is able to self-isolate and avoid exposure.

Moreover, social vulnerability has long been documented in people with $\mathrm{CD}$ [60], and groups with high burdens of $\mathrm{CD}$, including indigenous people, the rural poor, and migrants may face particular challenges in accessing healthcare. People living at or near the poverty level are also especially vulnerable to the economic impact of the pandemic, as experts have warned that years of gains in reducing poverty are now in jeopardy. The UN predicts that a global GDP shrinkage of 3.2\% in 2020, will push 34 million more people into extreme poverty [61]. The worsening economic situation threatens to make access to healthcare even more precarious for people living with $\mathrm{CD}$, who are often forced to make difficult decisions between spending time and money on healthcare or on other pressing priorities. Many work in the informal sector or in positions that do not offer paid time off or health insurance.

People with CD may feel more reluctant to seek care in a clinic for fear of exposure to COVID-19, and may, therefore, put off addressing complications related to $\mathrm{CD}$. Indeed, there have been reports of low utilization of services and delayed presentation for chronic conditions since the onset of the pandemic [62, 63]. Finally, CD can create a significant emotional burden for affected people who worry about the progression of the disease, and the pandemic may make it harder to access both mental health services and traditional support networks of families and friends. Patients with CD who acquire COVID-19 may experience particular concern and anxiety. As COVID-19 becomes a part of daily reality, creative responses will be needed from patient groups, social workers, mental health practitioners, and others to continue providing support to people with $C D$.

\section{Recommendations for Healthcare Providers Screening/testing of Chagas disease during the pandemic}

While the indications for screening and diagnosing CD are unchanged during the COVID-19 pandemic, the timing of testing depends on the degree to which the diagnosis of $C D$ will affect short term management of the individual being tested. Urgent testing remains appropriate for pregnant women, infants born to seropositive mothers, and any individual about to receive immunosuppression. Screening of blood donations also remains critical. Patients presenting with clinical syndromes suggestive of $\mathrm{CD}$ should also receive urgent testing to guide evaluation and therapy. Pregnant women from CDendemic countries should also be screened to evaluate for the possibility of maternal-fetal transmission. Depending on the circulation of SARS-CoV-2 in the community and local guidelines, widespread screening of individuals without symptoms from endemic countries could be postponed until it can be performed safely, with the understanding that while antiparasitic therapy may be indicated, it can generally be delayed until the patient can report for lab testing and follow-up visits without significant risk of exposure.

\section{Management of patients coinfected with Chagas disease and COVID-19}

Below, preliminary recommendations are provided for patients with CD who acquire COVID-19. The recommendations are divided depending on the patient's form of CD.

\section{Acute forms of $C D$}

Acute cases of $\mathrm{CD}$ following congenital, vector, or oral transmission, as well as those via transfusion, laboratory accidents, and other routes generally warrant antiparasitic treatment as early as possible, even in the context of the COVID-19 pandemic. If the patient is coinfected with COVID-19 and the acute form of CD, timely antiparasitic treatment of $\mathrm{CD}$ is needed, but clinicians should be mindful of the severity of COVID-19 symptoms. 


\section{Congenital $C D$}

Cases of congenital transmission are acute cases of $C D$, and treatment is effective with few side effects. COVID-19 is generally not severe in infants and children [64]. If the child does not have COVID-19 symptoms, antiparasitic treatment should be given as soon as the diagnosis of $T$. cruzi infection is established [37].

\section{Reactivation}

Patients must be admitted to the hospital and receive antiparasitic treatment with benznidazole for 60 days. However, if a full 60 days of treatment is not possible because of adverse events, treatment should still be continued for as close to 60 days as possible using anti-histaminic and/or anti-inflammatory drugs. Reactivation involving myocarditis/meningoencephalitis is of particular concern due to the occurrence of vascular/nervous system/myocardium involvement by COVID-19 and should be carefully monitored in an intensive care unit.

\section{Immunosuppression without reactivation}

In this case, antiparasitic treatment could be delayed until the patient can safely attend a clinic, depending on self-isolation guidelines and the risk of exposure to COVID-19. However, CD reactivation with signs in target organs should be closely monitored by clinical follow-up, direct microscopy (concentration methods) on peripheral blood and/or secretions [39], and, if possible, quantitative PCR during COVID-19 infection according to local protocols.

\section{Indeterminate chronic CD}

From an individual health management point of view, people with asymptomatic infection (in the indeterminate clinical form of $\mathrm{CD}$ ) are those in whom there is evidence of $T$. cruzi infection, but no evidence of organ damage (mainly cardiovascular or digestive), assessed by non-specific symptoms and low sensitivity tests to detect early organ damage, such as electrocardiogram, chest X-ray, and barium swallow and enema [65]. With or without antiparasitic treatment, regular monitoring is recommended to evaluate the clinical condition during follow-up and to quickly detect treatment failure and/or clinical progression.

As a general recommendation, and given the current epidemiological situation, it is important to assess the risk-benefit of referring a patient to a healthcare center. It is essential to preserve patient safety in terms of preventing new cases of COVID-19. However, it is also important from a public health perspective to optimize existing resources for health care. Outpatient visits as well as regular cardiovascular and gastrointestinal tests could be delayed if $\mathrm{CD}$ patients are stable. The use of telehealth tools for virtual consultation is highly recommended, including incorporating advice to patients about the need to contact healthcare facilities in case of the onset of symptoms, either from CD or possible COVID-19 infection.

\section{Etiological treatment of Chagas disease}

Etiological (antiparasitic) treatment in patients with CD without evidence of organ involvement is recommended for acute cases and most chronic cases in the indeterminate form or with only mild cardiomyopathy $[5,66]$. In the current context of the pandemic, however, two main aspects should be considered: 1) drug characteristics and potential interactions with current treatment of COVID-19, and 2) the urgency of the indication for anti-T. cruzi drugs.

\section{Drug characteristics}

Benznidazole (BZN) and nifurtimox (NFX) are the two drugs accepted by regulatory agencies for antiparasitic treatment of CD. BZN (N-benzyl-2-nitro-1-imidazole acetamide) is a nitroimidazole that inhibits DNA, RNA, and protein synthesis of T. cruzi. NFX (5-nitrofuran 3-methyl-4-(5'-nitrofurfurylideneamine) tetrahydro-4H-1,4-tiazine-1,1-dioxide) is a nitrofuran derivative whose mechanism of action involves various reduction and oxidation reactions of its nitro constituent, leading to the production by parasite enzymes of a variety of reactive oxygen species that react with cellular macromolecules and are lethal to the parasite. NFX also leads to the inactivation of a critical trypanosomal enzyme, trypanothione reductase [67].

In both cases, the mechanism of action is not completely described, and exploration of the potential interactions between BZN and NFX with most common drugs used in COVID-19 management should be taken into consideration and further explored. Due to the hepatic metabolism of BZN $(95 \%)$ and NFX (>99\%), hepatotoxicity in combination with anti-COVID-19 drugs must be monitored. 
Treatment indications and follow-up of patients under treatment

Etiological treatment of T. cruzi infection is an emergency only under very specific circumstances [68]. Even if adverse drug reactions (ADRs) related to BZN and NFX are non-severe in most cases [69], close follow-up of patients who start a BZN or NFX regime is recommended to identify side effects promptly and to monitor hepatic and hematologic function [54, 70, 71]. During the pandemic, delaying initiation of etiological treatment regimens for chronic T. cruzi infection without organ involvement is a valid course of action in healthcare settings, to avoid unnecessary exposure to COVID-19 and because of limitations in follow-up due to decreased in-person care. Nevertheless, patients diagnosed with COVID-19 may receive immunosuppressive therapy, and close monitoring to diagnose $\mathrm{CD}$ reactivation early in its course is recommended. In the case of clinical and/or parasitological evidence of reactivation, starting treatment with BZN or NFX is considered an emergency [68].

If a patient is already receiving BZN or NFX, treatment should be continued, and self-quarantine measures to avoid COVID-19 should be taken. Telehealth tools for treatment follow-up are recommended as well as minimization of contact with healthcare facilities, which would primarily only be indicated to perform laboratory tests usually recommended during treatment to monitor hepatotoxicity and hemogram alterations due to BZN or NFX, or in the event of concerning ADRs. If a patient under treatment with BZN or NFX develops symptomatic COVID-19 infection providers could consider on a case-by-case basis whether to interrupt treatment, depending on the severity of symptoms and the type of treatment required. There is no evidence of drug-drug interaction between antiparasitics for $\mathrm{CD}$ and the drugs currently under investigation to treat COVID-19; treatment of $\mathrm{CD}$ in the indeterminate form is non-urgent.

Table 1 summarizes guidance for providing etiological treatment of $\mathrm{CD}$ during the pandemic, taking into account both the patient's form of CD and their COVID-19 status.

In all cases, etiological treatment of Chagas disease should be accompanied by appropriate close followup, including liver enzymes and blood count parameters. See Echeverria et al. 2020 [68].

\section{Management of patients with Chagas cardiomyopathy and COVID-19}

COVID-19 has been associated with multiple cardiac manifestations that include cardiac arrhythmias, Type 2 and 1 myocardial infarction, heart failure exacerbations and acute fulminant myocarditis [72, 73]. Potential interactions between COVID-19 and CCC may be expected primarily due to the common immunological

Table 1: Etiological treatment recommendations for Chagas disease in the context of COVID-19 coinfection.*

\begin{tabular}{|c|c|c|}
\hline Chagas disease status & COVID-19 status & $\begin{array}{l}\text { Guidance for etiological treatment with benznidazole } \\
\text { or nifurtimox }\end{array}$ \\
\hline Chronic, indeterminate & Negative & $\begin{array}{l}\text { Consider delaying treatment to minimize risk of COVID-19 exposure } \\
\text { based on local epidemiological context and current physical } \\
\text { distancing regulations. }\end{array}$ \\
\hline Chronic, indeterminate & $\begin{array}{l}\text { Positive, with or } \\
\text { without symptoms }\end{array}$ & $\begin{array}{l}\text { Consider delaying treatment until COVID- } 19 \text { is completely resolved } \\
\text { and based on local epidemiological context and current physical } \\
\text { distancing regulations. }\end{array}$ \\
\hline Acute cases & $\begin{array}{l}\text { Negative or } \\
\text { positive, with or } \\
\text { without symptoms }\end{array}$ & Initiate treatment. \\
\hline $\begin{array}{l}\text { Clinical and/ } \\
\text { or parasitological } \\
\text { evidence of reactivation }\end{array}$ & $\begin{array}{l}\text { Negative or posi- } \\
\text { tive, with or with- } \\
\text { out symptoms }\end{array}$ & Initiate treatment. \\
\hline $\begin{array}{l}\text { Chronic, indeterminate, } \\
\text { currently undergoing } \\
\text { etiological treatment }\end{array}$ & $\begin{array}{l}\text { Positive, sympto- } \\
\text { matic }\end{array}$ & $\begin{array}{l}\text { Postpone treatment; if immunosuppressive drugs are prescribed in } \\
\text { the context of COVID-19 management, closely monitor for reactiva- } \\
\text { tion of } T \text {. cruzi infection by direct microscopy on peripheral blood or } \\
\text { fluids and/or quantitative PCR (if available). If reactivation is evident, } \\
\text { restart benznidazole/nifurtimox treatment. }\end{array}$ \\
\hline $\begin{array}{l}\text { Chronic, indeterminate, } \\
\text { currently undergoing }\end{array}$ & $\begin{array}{l}\text { Positive, } \\
\text { asymptomatic }\end{array}$ & Continue treatment. \\
\hline
\end{tabular}

etiological treatm 
pathways shared by the diseases, as angiotensin-converting enzyme 2 (ACE2) is involved in heart function and the development of hypertension and diabetes mellitus, risk factors frequently observed in patients with CCC. ACE2 levels can be increased by the use of ACE inhibitors and/or angiotensin receptor blockers (ARBs) which are frequently used for the management of CCC. There is no evidence to date to support discontinuation of either ACE inhibitors or ARBs based on the theoretical potential of increasing the susceptibility to COVID-19 infection. Most cardiovascular societies including ESC, ACC, AHA, CCS, and the IASC have indicated that these medications should be continued regardless of the presence of concomitant COVID-19 manifestations. This should also be the case for patients with CCC.

Other potential interactions may occur in patients with CCC currently treated for cardiac arrhythmias, such as atrial fibrillation or life-threatening ventricular arrhythmias receiving amiodarone, as the potential for increased QT interval with treatments that have been proposed for COVID-19 such as hydroxychloroquine and/or azithromycin may increase the risk of torsade de points.

Patients with CCC must continue their usual treatments during the COVID-19 pandemic. Outpatient clinics may use telehealth, if available, to avoid putting these vulnerable patients at risk of SARS-CoV-2 infection. With proper hygiene and self-care measures, cardiac tests like EKG, echo, stress tests, or Holter may be performed or slightly delayed, always weighing risk-benefit and regional SARS-CoV-2 circulation status. If a patient with CCC develops new arrhythmias, stroke, or acute or worsening chronic heart failure, hospitalization must not be delayed. As hospitals in some regions may be severely strained by COVID-19, care of these acute events may be compromised, putting CCC patients at risk.

Table 2 lists potential interactions between cardiovascular drugs used to treat CCC and some proposed COVID-19 treatments.

Table 2: Potential interactions between COVID-19 treatments under investigation and CCM drugs.

\section{COVID-19 treatments under investigation Potential interactions with CCM drugs}

Chloroquine-hydroxychloroquine

Protease inhibitors (lopinavir-ritonavir)

Azithromycin

Atazanavir

Remdesivir

Favipiravir, Bevacizumab, Ecolizumab, Fingolimod, Pirfenidone, Interferon Methylprednisone

Tocilizumab

Nitazoxanide

Sarilumab

Interferon and Methylprednisolone

Ribavirin

Ivermectin
Inhibits CYP2D6 (increasing half-life of most of the beta blockers [74] and amiodarone), and inhibits and downregulates PgP [75]. They do not interact with novel oral anticoagulants (NOACS) or vitamin $\mathrm{K}$ antagonists (VKAs) [76].

By inhibiting CYP3A4, they increase plasma levels of most of CV drugs. May lower the effect of VKAs by induction of CYP2C19 and increase plasma levels of NOACs. Also may increase amiodarone levels [77].

Increases levels of warfarin/acenocoumarol, these anticoagulants should be withdrawn during azithromycin treatment. Due to PgP inhibition, dose reduction of NOACs may be required.

Increases levels of VKAs and NOACs (should be discontinued). May increase amiodarone levels and effect. May increase digoxin levels. Mild increase in atenolol levels (beta blocker) [77].

No relevant interactions.

No relevant interactions.

May lower effect of anticoagulants.

May increase VKA levels; do not use concomitantly.

It is a CYP3A4 inducer, but dose modifications are not recommended.

Reduction of VKAs is advised.

Interferes with the absorption of VKAs, possible dose increase indicated. Enalapril and other ACE2 inhibitors may provoke dry cough as well as ribavirin [78].

May decrease the effect of warfarin and dicoumarol. Risk of myopathy with captopril [79]. 
COVID-19 treatments under investigation Potential interactions with CCM drugs

\begin{tabular}{|c|c|}
\hline Oseltamivir & $\begin{array}{l}\text { No CYP interactions with CV drugs. However, case reports and series } \\
\text { show some increase in the effect of VKAs [75]. }\end{array}$ \\
\hline Arbidol (Umifenovir) & May decrease metabolism of labetalol (beta-blocker) [80]. \\
\hline Canakinumab & $\begin{array}{l}\text { No known drug interactions, but upregulation of CYP enzymes may } \\
\text { further modify metabolization of CV drugs }[81,82] \text {. }\end{array}$ \\
\hline Anakinra & No drug interactions. \\
\hline Emapalumab & $\begin{array}{l}\text { No known drug interactions, but upregulation of CYP enzymes may } \\
\text { further modify metabolization of CV drugs [83]. }\end{array}$ \\
\hline Siltuximab & VKA interaction through CYP3450. Close monitoring [84]. \\
\hline Cyclosporin A & $\begin{array}{l}\text { Cyclosporin may increase digoxin levels. Amiodarone, losartan, } \\
\text { and valsartan increase cyclosporin levels; ACE inhibitors increase } \\
\text { nephrotoxicity }[85,86] \text {. }\end{array}$ \\
\hline Sirolimus & $\begin{array}{l}\text { Serious warning; may increase risk of ACE inhibitor related angi- } \\
\text { oedema. CYP450 and PgP interactions [87]. }\end{array}$ \\
\hline Darunavir/cobicistat & $\begin{array}{l}\text { Drugs metabolized by CYP3A4, CYP2D6, or that use the transporters } \\
\text { PgP, BCRP, MATE1, OATP1B1 or OATP1B3 may have interactions [88]. } \\
\text { Anticoagulants, beta blockers, and digoxin should be used with } \\
\text { caution. }\end{array}$ \\
\hline
\end{tabular}

Table 3: Understanding the interactions between COVID-19 and CD: Gaps and needs.

\begin{tabular}{|c|c|c|}
\hline Disease interaction & Clinical questions & Drug development needs \\
\hline $\begin{array}{l}\text { How is the natural history of CD } \\
\text { affected by COVID-19? } \\
\text { Can the cytokine storm trigger } \\
\text { reactivation of parasitemia? } \\
\text { - Does the cytokine storm trigger } \\
\text { disease progression? } \\
\text { - Do viral and parasitic immune } \\
\text { response pathways cross react? } \\
\text { Does the chronic inflammatory } \\
\text { state of CD lead to more severe } \\
\text { COVID-19 disease? } \\
\text { Does the prothrombotic state } \\
\text { from both diseases behave } \\
\text { synergistically? }\end{array}$ & $\begin{array}{l}\text { What precautions are necessary } \\
\text { regarding COVID-19 treatment in } \\
\text { CD patients? } \\
\text { - What are the hemodynamic and } \\
\text { arrhythmic risks of COVID-19 in } \\
\text { patients with CCC? } \\
\text { - What is the impact of delaying } \\
\text { CD treatments during COVID-19 } \\
\text { infection? } \\
\text { - What is the impact of delays } \\
\text { in access to CD diagnosis and } \\
\text { cardiac evaluation? } \\
\text { - What is the impact of possible } \\
\text { health system collapse on qual- } \\
\text { ity of care of CD patients with } \\
\text { symptomatic disease? }\end{array}$ & $\begin{array}{l}\text { What are the antiviral effects } \\
\text { of antiparasitic drugs for CD } \\
\text { (BZN and NFX)? } \\
\text { · Can anti-inflammatory drugs } \\
\text { improve host response to COVID- } \\
19 \text { and complement antiparasitic } \\
\text { treatment of CD? } \\
\text { · Can allopurinol or colchicine help } \\
\text { delay or avoid complications for } \\
\text { both diseases? } \\
\text { - Is full anticoagulant therapy useful } \\
\text { for COVID-19 [89] and CD [90]? } \\
\text { - Could CV CD treatments such as } \\
\text { amiodarone treat COVID-19? }\end{array}$ \\
\hline
\end{tabular}

\section{Future needs}

Our current understanding of the potential interrelations between CD and COVID-19 is still limited; there are substantial needs for future research. The recommendations provided in this document should be considered preliminary and may require refinement and adjustment as our understanding of both diseases develops. Table 3 lists some of the most important gaps in our current clinical knowledge. Research from other disciplines will also be needed to better understand the epidemiology of both diseases, the social and psychological impacts of the pandemic on people with $\mathrm{CD}$, new access barriers that emerge in the context of the pandemic and the economic dislocation it causes, and the particular contexts of vulnerable populations including migrants and indigenous communities.

\section{Conclusion}

While global in scope and indiscriminate in whom it infects, COVID-19 poses a particular risk to people with CD. Both diseases are more prevalent in marginalized populations, whose access to appropriate care is limited, and whose exposure to risk factors is proportionally higher. COVID-19 is more lethal in indi- 
Table 4: Potential impact of COVID-19 on CD healthcare roadblocks.

\begin{tabular}{|c|c|}
\hline Area & Potential impact of SARS-CoV-2 on key roadblocks \\
\hline Prevention & $\begin{array}{l}\text {-Reduced commitment from governments } \\
\text {-Diversion of clinical research to COVID-19 } \\
\text {-Public health resources diverted to COVID-19 } \\
\text {-Lower media interest in neglected diseases } \\
\text {-Limitations on health fairs, campaigns, and community events }\end{array}$ \\
\hline Diagnosis & $\begin{array}{l}\text {-Decreased visits to healthcare facilities out of fear of contagion } \\
\text {-Testing/laboratory resources strained by COVID-19 }\end{array}$ \\
\hline Etiological treatment & $\begin{array}{l}\text {-Decreased visits to healthcare facilities out of fear of contagion } \\
\text {-Healthcare personnel strained by COVID-19 } \\
\text {-Lack of knowledge on drug interactions with COVID-19, or } \\
\text { with COVID-19 drugs }\end{array}$ \\
\hline Diagnosis and treatment of clinical complications & $\begin{array}{l}\text {-Limited knowledge of interaction between COVID-19 } \\
\text { and CCC } \\
\text {-Potential impact of COVID- } 19 \text { drugs on CCC } \\
\text {-Strains on health facilities' ability to manage CCC }\end{array}$ \\
\hline Psychosocial & $\begin{array}{l}\text {-Increasing poverty due to economic impact of pandemic } \\
\text {-Isolation from support networks } \\
\text {-Fears about susceptibility to COVID-19 because of CD diagnosis }\end{array}$ \\
\hline
\end{tabular}

viduals with cardiac disease and/or other cardiac risk factors, such as diabetes and obesity, which are also prevalent in individuals with CD. The mechanisms of COVID-19 disease, while not completely understood, theoretically pose a risk of both exacerbation of cardiac dysfunction from $\mathrm{CD}$ and acute reactivation of $\mathrm{CD}$ due either to disease-induced immunomodulation or therapeutic immunosuppression. The economic impact of the pandemic hits hardest in the lowest socioeconomic strata, further complicating the ability of many individuals with $\mathrm{CD}$ to obtain the treatment they need for either illness. Efforts to mitigate the spread of COVID-19, by limiting medical facilities to all but the most urgent care, complicates efforts to diagnose, treat, and monitor patients with $\mathrm{CD}$, which may lead to clinical deterioration, increased maternal-fetal transmission, and underdiagnosis, all of which were significant concerns even before the onset of the pandemic.

Roadblocks to accessing proper care for CD were recently described in the WHF-IASC Roadmap on CD [5]. Using a similar framework, Table 4 assesses the potential effect of the pandemic on key roadblocks to CD healthcare.

The end of the pandemic in Latin America is still far from sight and its full impact on healthcare and healthcare access, in particular, remains to be seen. CD has long been a hidden disease, with low awareness among healthcare professionals and people at risk, and limited commitment from governments. In the short-term, as public health resources are intently focused on mitigating the pandemic, it could become even more of a challenge to raise awareness of $\mathrm{CD}$. At the same time, the pandemic could serve as an opportunity to strengthen public concern for addressing comorbid conditions and meeting the healthcare needs of underserved populations. Still, the current reality requires us to rethink traditional approaches to CD and other neglected diseases, to ensure we continue to make progress toward their eradication even as new public health challenges emerge. Ultimately, neither CD nor COVID-19 can be separated from their socioeconomic context, and winning the struggle against both diseases will involve implementing comprehensive programs that focus on strengthening the healthcare rights and access of the marginalized people who are currently most impacted.

\section{Acknowledgements}

The authors would like to thank Marina Certo, DNDi Platforms Coordination Officer, for invaluable support of the writing group. DNDi is grateful to its donors, public and private, who have provided funding to DNDi since its inception in 2003. A full list of DNDi donors can be found at http://www.dndi.org/donors/donors. MASY is grateful for financial support from FAPESP 2012/50273-0. ALPR is grateful for support from CNPq (310679/2016-8 and 465518/2014-1) and FAPEMIG (PPM-00428-17).

\section{Competing Interests}

The authors have no competing interests to declare. 


\section{Author Contributions}

All authors contributed to the drafting and review of the manuscript.

\section{Publisher's Note}

This paper underwent peer review using the Cross-Publisher COVID-19 Rapid Review Initiative.

\section{References}

1. Rassi A, Jr, Rassi A, Marin-Neto JA. Chagas disease. The Lancet. 2010; 375(9723): 1388-402. DOI: https://doi.org/10.1016/S0140-6736(10)60061-X

2. Johns Hopkins Coronavirus Resource Center. COVID-19 Dashboard by the Center for Systems Science and Engineering (CSSE) at Johns Hopkins University (JHU) 2020 [updated and accessed September 4, 2020]. Available from: https://coronavirus.jhu.edu/map.html.

3. World Health Organization. Chagas disease in Latin America: An epidemiological update based on 2010 estimates Weekly Epidemiological Record. 2015; 90(6): 33-44.

4. World Health Organization. Fourth WHO Report on Neglected Tropical Diseases. Geneva; 2017.

5. Echeverría LE, Marcus R, Novick G, Sosa-Estani S, Ralston K, Zaidel EJ, et al. WHF IASC Roadmap on Chagas Disease. Global Heart. 2020; 15(1): 26. DOI: https://doi.org/10.5334/gh.484

6. Ribeiro AL, Nunes MP, Teixeira MM, Rocha MOC. Diagnosis and management of Chagas disease and cardiomyopathy. Nature Reviews Cardiology. 2012; 9(10): 576-589. DOI: https://doi.org/10.1038/ nrcardio.2012.109

7. Oudit GY, Kassiri Z, Jiang C, Liu PP, Poutanen SM, Penninger JM, et al. SARS-coronavirus modulation of myocardial ACE2 expression and inflammation in patients with SARS. European Journal of Clinical Investigation. 2009; 39(7): 618-625. DOI: https://doi.org/10.1111/j.1365-2362.2009.02153.x

8. Chen L, Li X, Chen M, Feng Y, Xiong C. The ACE2 expression in human heart indicates new potential mechanism of heart injury among patients infected with SARS-CoV-2. Cardiovascular Research. 2020; 116(6): 1097-1100. DOI: https://doi.org/10.1093/cvr/cvaa078

9. Rassi A, Amato Neto V, de Siqueira AF, Ferriolli Filho F, Amato VS, Rassi Júnior A. [Protective effect of benznidazole against parasite reactivation in patients chronically infected with Trypanosoma cruzi and treated with corticoids for associated diseases]. Revista da Sociedade Brasileira de Medicina Tropical. 1999; 32(5): 475-482. DOI: https://doi.org/10.1590/S0037-86821999000500002

10. dos Santos-Neto LL, Polcheira MF, Castro C, Lima RA, Simaan CK, Corrêa-Lima FA. [Trypanosoma cruzi high parasitemia in patient with systemic lupus erythematosus]. Revista da Sociedade Brasileira de Medicina Tropical. 2003; 36(5): 613-615. DOI: https://doi.org/10.1590/S0037-86822003000500012

11. López L, Arai K, Giménez E, Jiménez M, Pascuzo C, Rodríguez-Bonfante C, et al. [C-reactive protein and interleukin- 6 serum levels increase as Chagas disease progresses towards cardiac failure]. Revista Española de Cardiología. 2006; 59(1): 50-56. DOI: https://doi.org/10.1016/S1885-5857(06)60048-0

12. Keating SM, Deng X, Fernandes F, Cunha-Neto E, Ribeiro AL, Adesina B, et al. Inflammatory and cardiac biomarkers are differentially expressed in clinical stages of Chagas disease. International Journal of Cardiology. 2015; 199: 451-459. DOI: https://doi.org/10.1016/j.ijcard.2015.07.040

13. Benziger CP, do Carmo GAL, Ribeiro ALP. Chagas cardiomyopathy: Clinical presentation and management in the Americas. Cardiology Clinics. 2017; 35(1): 31-47. DOI: https://doi.org/10.1016/j. ccl.2016.08.013

14. Tanowitz HB, Machado FS, Spray DC, Friedman JM, Weiss OS, Lora JN, et al. Developments in the management of Chagas cardiomyopathy. Expert Review of Cardiovascular Therapy. 2015; 13(12): 1393-1409. DOI: https://doi.org/10.1586/14779072.2015.1103648

15. Guzik TJ, Mohiddin SA, Dimarco A, Patel V, Savvatis K, Marelli-Berg FM, et al. COVID-19 and the cardiovascular system: Implications for risk assessment, diagnosis, and treatment options. Cardiovascular Research. 2020; 116(10): 1666-1687. DOI: https://doi.org/10.1093/cvr/cvaa106

16. Schett G, Sticherling M, Neurath MF. COVID-19: Risk for cytokine targeting in chronic inflammatory diseases? Nature Reviews Immunology. 2020; 20(5): 271-272. DOI: https://doi.org/10.1038/s41577020-0312-7

17. de Araújo FF, Lima Torres KC, Viana Peixoto S, Pinho Ribeiro AL, Vaz Melo Mambrini J, Bortolo Rezende V, et al. CXCL9 and CXCL10 display an age-dependent profile in Chagas patients: A cohort study of aging in Bambui, Brazil. Infectious diseases of poverty. 2020; 9(1): 51. DOI: https://doi. org/10.1186/s40249-020-00663-w

18. Dutra WO, Menezes CA, Magalhães LM, Gollob KJ. Immunoregulatory networks in human Chagas disease. Parasite Immunology. 2014; 36(8): 377-387. DOI: https://doi.org/10.1111/pim.12107 
19. Siripanthong B, Nazarian S, Muser D, Deo R, Santangeli P, Khanji MY, et al. Recognizing COVID19-related myocarditis: The possible pathophysiology and proposed guideline for diagnosis and management. Heart Rhythm. 2020; 17(9): 1463-1471. DOI: https://doi.org/10.1016/j.hrthm.2020.05.001

20. Bikdeli B, Madhavan MV, Jimenez D, Chuich T, Dreyfus I, Driggin E, et al. COVID-19 and thrombotic or thromboembolic disease: Implications for prevention, antithrombotic therapy, and follow-Up: JACC state-of-the-art review. Journal of the American College of Cardiology. 2020; 75(23): 2950-2973. DOI: https://doi.org/10.1016/j.jacc.2020.04.031

21. Pinazo MJ, de Posada EJ, Izquierdo L, Tassies D, Marques AF, de Lazzari E, et al. Altered hypercoagulability factors in patients with chronic Chagas disease: Potential biomarkers of therapeutic response. PLoS Neglected Tropical Diseases. 2016; 10(1): e0004269. DOI: https://doi.org/10.1371/ journal.pntd.0004269

22. Nunes MCP, Beaton A, Acquatella H, Bern C, Bolger AF, Echeverría LE, et al. Chagas cardiomyopathy: An update of current clinical knowledge and management: A scientific statement From the American Heart Association. Circulation. 2018; 138(12): e169-e209. DOI: https://doi.org/10.1161/ CIR.0000000000000599

23. Sosa-Estani S, Cura E, Velazquez E, Yampotis C, Segura EL. Etiological treatment of young women infected with Trypanosoma cruzi, and prevention of congenital transmission. Revista da Sociedade Brasileira de Medicina Tropical. 2009; 42(5): 484-487. DOI: https://doi.org/10.1590/S003786822009000500002

24. Fabbro DL, Danesi E, Olivera V, Codebó MO, Denner S, Heredia C, et al. Trypanocide treatment of women infected with Trypanosoma cruzi and its effect on preventing congenital Chagas. PLoS Neglected Tropical Diseases. 2014; 8(11): e3312. DOI: https://doi.org/10.1371/journal.pntd.0003312

25. Regueiro A, García-Álvarez A, Sitges M, Ortiz-Pérez JT, De Caralt MT, Pinazo MJ, et al. Myocardial involvement in Chagas disease: Insights from cardiac magnetic resonance. International Journal of Cardiology. 2013; 165(1): 107-12. DOI: https://doi.org/10.1016/j.ijcard.2011.07.089

26. Nunes MCP, Badano LP, Marin-Neto JA, Edvardsen T, Fernández-Golfín C, Bucciarelli-Ducci C, et al. Multimodality imaging evaluation of Chagas disease: An expert consensus of Brazilian Cardiovascular Imaging Department (DIC) and the European Association of Cardiovascular Imaging (EACVI). European Heart Journal Cardiovascular Imaging. 2018; 19(4): 459-460n. DOI: https://doi. org/10.1093/ehjci/jex154

27. Torreão JA, Ianni BM, Mady C, Naia E, Rassi CH, Nomura C, et al. Myocardial tissue characterization in Chagas' heart disease by cardiovascular magnetic resonance. Journal of Cardiovascular Magnetic Resonance. 2015; 17: 97. DOI: https://doi.org/10.1186/s12968-015-0200-7

28. Barros ML, Ribeiro A, Nunes Mdo C, Rocha MO. [Association between left ventricular wall motion abnormalities and ventricular arrhythmia in the indeterminate form of Chagas disease]. Revista da Sociedade Brasileira de Medicina Tropical. 2011; 44(2): 213-216. DOI: https://doi.org/10.1590/S003786822011005000020

29. Furtado RG, Frota D, Silva JB, Romano MM, Almeida Filho OC, Schmidt A, et al. Right ventricular Doppler echocardiographic study of indeterminate form of Chagas disease. Arquivos Brasileiros de Cardiologia. 2015; 104(3): 209-217. DOI: https://doi.org/10.5935/abc.20140197

30. Cianciulli TF, Saccheri MC, Papantoniou A, Méndez RJ, Gagliardi JA, Prado NG, et al. Use of tissue doppler imaging for the early detection of myocardial dysfunction in patients with the indeterminate form of Chagas disease. Revista da Sociedade Brasileira de Medicina Tropical. 2020; 53: e20190457. DOI: https://doi.org/10.1590/0037-8682-0457-2019

31. Jin X, Lian JS, Hu JH, Gao J, Zheng L, Zhang YM, et al. Epidemiological, clinical and virological characteristics of 74 cases of coronavirus-infected disease 2019 (COVID-19) with gastrointestinal symptoms. Gut. 2020; 69(6): 1002-1009. DOI: https://doi.org/10.1136/gutjnl-2020-320926

32. Lin L, Jiang X, Zhang Z, Huang S, Zhang Z, Fang Z, et al. Gastrointestinal symptoms of 95 cases with SARS-CoV-2 infection. Gut. 2020; 69(6): 997-1001. DOI: https://doi.org/10.1136/gutjnl-2020-321013

33. Nath A. Neurologic complications of coronavirus infections. Neurology. 2020; 94(19): 809-810. DOI: https://doi.org/10.1212/WNL.0000000000009455

34. Montalvan V, Lee J, Bueso T, De Toledo J, Rivas K. Neurological manifestations of COVID-19 and other coronavirus infections: A systematic review. Clinical Neurology and Neurosurgery. 2020; 194 : 105921. DOI: https://doi.org/10.1016/j.clineuro.2020.105921

35. Howard EJ, Xiong X, Carlier Y, Sosa-Estani S, Buekens P. Frequency of the congenital transmission of Trypanosoma cruzi: a systematic review and meta-analysis. BJOG. 2014; 121(1): 22-33. DOI: https:// doi.org/10.1111/1471-0528.12396 
36. Kaplinski M, Jois M, Galdos-Cardenas G, Rendell VR, Shah V, Do RQ, et al. Sustained domestic vector exposure is associated with increased Chagas cardiomyopathy risk but decreased parasitemia and congenital transmission risk among young women in Bolivia. Clinical Infectious Diseases. 2015; 61(6): 918-926. DOI: https://doi.org/10.1093/cid/civ446

37. Carlier Y, Altcheh J, Angheben A, Freilij H, Luquetti AO, Schijman AG, et al. Congenital Chagas disease: Updated recommendations for prevention, diagnosis, treatment, and follow-up of newborns and siblings, girls, women of childbearing age, and pregnant women. PLoS Neglected Tropical Diseases. 2019; 13(10): e0007694. DOI: https://doi.org/10.1371/journal.pntd.0007694

38. Buekens P, Alger J, Bréart G, Cafferata ML, Harville E, Tomasso G. A call for action for COVID19 surveillance and research during pregnancy. The Lancet Global health. 2020; 8(7): e877-e8. DOI: https://doi.org/10.1016/S2214-109X(20)30206-0

39. Sartori AM, Ibrahim KY, Nunes Westphalen EV, Braz LM, Oliveira OC, Jr, Gakiya E, et al. Manifestations of Chagas disease (American trypanosomiasis) in patients with HIV/AIDS. Annals of Tropical Medicine and Parasitology. 2007; 101(1): 31-50. DOI: https://doi.org/10.1179/136485907X154629

40. Gosain R, Abdou Y, Singh A, Rana N, Puzanov I, Ernstoff MS. COVID-19 and cancer: A comprehensive review. Current Oncology Reports. 2020; 22(5): 53. DOI: https://doi.org/10.1007/ s11912-020-00934-7

41. Zingone F, Savarino EV. Viral screening before initiation of biologics in patients with inflammatory bowel disease during the COVID-19 outbreak. The Lancet Gastroenterology \& Hepatology. 2020; 5(6): 525. DOI: https://doi.org/10.1016/S2468-1253(20)30085-6

42. Manne-Goehler J, Umeh CA, Montgomery SP, Wirtz VJ. Estimating the burden of Chagas disease in the United States. PLoS Neglected Tropical Diseases. 2016; 10(11): e0005033. DOI: https://doi. org/10.1371/journal.pntd.0005033

43. Lima-Costa MF, Peixoto SV, Ribeiro ALP. Chagas disease and mortality in old age as an emerging issue: 10 year follow-up of the Bambuí population-based cohort study (Brazil). International Journal of Cardiology. 2010; 145(2): 362-363. DOI: https://doi.org/10.1016/j.ijcard.2010.02.036

44. Martins-Melo FR, Ramos AN, Jr, Alencar CH, Heukelbach J. Prevalence of Chagas disease in Brazil: A systematic review and meta-analysis. Acta Tropica. 2014; 130: 167-174. DOI: https://doi. org/10.1016/j.actatropica.2013.10.002

45. Zhou F, Yu T, Du R, Fan G, Liu Y, Liu Z, et al. Clinical course and risk factors for mortality of adult inpatients with COVID-19 in Wuhan, China: A retrospective cohort study. Lancet. 2020; 395(10229): 1054-1062. DOI: https://doi.org/10.1016/S0140-6736(20)30566-3

46. Verity R, Okell LC, Dorigatti I, Winskill P, Whittaker C, Imai N, et al. Estimates of the severity of coronavirus disease 2019: A model-based analysis. The Lancet Infectious Diseases. 2020; 20(6): 669-677. DOI: https://doi.org/10.1016/S1473-3099(20)30243-7

47. Centers for Disease Control. CDC COVID Data Tracker 2020 [updated June 30, 2020]. Available from: https://www.cdc.gov/covid-data-tracker/index.html\#demographics.

48. Li B, Yang J, Zhao F, Zhi L, Wang X, Liu L, et al. Prevalence and impact of cardiovascular metabolic diseases on COVID-19 in China. Clinical Research in Cardiology. 2020; 109(5): 531-538. DOI: https:// doi.org/10.1007/s00392-020-01626-9

49. Wang D, Hu B, Hu C, Zhu F, Liu X, Zhang J, et al. Clinical characteristics of 138 hospitalized patients with 2019 novel coronavirus-infected pneumonia in Wuhan, China. Jama. 2020; 323(11): 1061-1069. DOI: https://doi.org/10.1001/jama.2020.1585

50. Moccia F, Gerbino A, Lionetti V, Miragoli M, Munaron LM, Pagliaro P, et al. COVID-19-associated cardiovascular morbidity in older adults: A position paper from the Italian Society of Cardiovascular Researches. GeroScience. 2020; 42(4): 1021-1049. DOI: https://doi.org/10.1007/ s11357-020-00198-w

51. Imam Z, Odish F, Gill I, O'Connor D, Armstrong J, Vanood A, et al. Older age and comorbidity are independent mortality predictors in a large cohort of 1305 COVID-19 patients in Michigan, United States. Journal of Internal Medicine. 2020; 288(4). DOI: https://doi.org/10.1111/joim.13119

52. Alves RM, Thomaz RP, Almeida EA, Wanderley JdaS, Guariento ME. Chagas' disease and ageing: The coexistence of other chronic diseases with Chagas' disease in elderly patients. Revista da Sociedade Brasileira de Medicina Tropical. 2009; 42(6): 622-628. DOI: https://doi.org/10.1590/ S0037-86822009000600002

53. Oliveira Junior LR, Carvalho TB, da Costa ÉAPN, Marques Pereira PC, Kurokawa CS. Cardiovascular comorbidities in patients with chronic Chagas disease. AME Medical Journal. 2018. DOI: https:// doi.org/10.21037/amj.2018.07.01 
54. Jackson Y, Castillo S, Hammond P, Besson M, Brawand-Bron A, Urzola D, et al. Metabolic, mental health, behavioural and socioeconomic characteristics of migrants with Chagas disease in a nonendemic country. Tropical Medicine \& International Health. 2012; 17(5): 595-603. DOI: https://doi. org/10.1111/j.1365-3156.2012.02965.x

55. Wu Z, McGoogan JM. Characteristics of and important lessons from the coronavirus disease 2019 (COVID-19) outbreak in China: Summary of a report of 72314 cases from the Chinese Center for Disease Control and Prevention. Jama. 2020; 323(13): 1239-1242. DOI: https://doi.org/10.1001/ jama.2020.2648

56. Onder G, Rezza G, Brusaferro S. Case-fatality rate and characteristics of patients dying in relation to COVID-19 in Italy. Jama. 2020; 323(18): 1775-1776. DOI: https://doi.org/10.1001/jama.2020.4683

57. Centers for Disease Control. Provisional death counts for coronavirus disease 2019 (COVID-19): Race and Hispanic origin 2020 [updated June 24, 2020]. Available from: https://www.cdc.gov/nchs/ nvss/vsrr/covid_weekly/index.htm\#Race_Hispanic.

58. Batista A, Antunes B, Faveret G, Peres I, Marchesi J, Cunha JP, et al. Análise socioeconômica da taxa de letalidade da COVID-19 no Brasil. Nucleo de Operacoes e Inteligencia em Saude (NOIS); 2020 May 27, 2020. Contract No.: Nota Tecnica 11. Available from: https://www.sites.google.com/view/ nois-pucrio/publica\%C3\%A7\%C3\%B5es?authuser=0\#h.ijqa5msfttoq

59. Baqui P, Bica I, Marra V, Ercole A, van der Schaar M. Ethnic and regional variations in hospital mortality from COVID-19 in Brazil: A cross-sectional observational study. The Lancet Global Health. 2020; 8(8): E1018-E1026. DOI: https://doi.org/10.1016/S2214-109X(20)30285-0

60. Viotti R, Vigliano CA, Alvarez MG, Lococo BE, Petti MA, Bertocchi GL, et al. The impact of socioeconomic conditions on chronic Chagas disease progression. Revista Española de Cardiología. 2009; 62(11): 1224-1232. DOI: https://doi.org/10.1016/S1885-5857(09)73349-3

61. United Nations. World Economic Situation and Prospects as of mid-2020. New York, NY; 2020. Available from: https://www.un.org/development/desa/dpad/wp-content/uploads/sites/45/publication/ WESP2020_MYU_Report.pdf.

62. Pessoa-Amorim G, Camm CF, Gajendragadkar P, De Maria GL, Arsac C, Laroche C, et al. Admission of patients with STEMI since the outbreak of the COVID-19 pandemic: A survey by the European Society of Cardiology. European Heart Journal - Quality of Care and Clinical Outcomes. 2020; 6(3): 210-216. DOI: https://doi.org/10.1093/ehjqcco/qcaa046

63. Reza N, DeFilippis EM, Jessup M. Secondary impact of the COVID-19 pandemic on patients with heart failure. Circulation: Heart Failure. 2020; 13(5): e007219. DOI: https://doi.org/10.1161/CIRCHEARTFAILURE.120.007219

64. Mustafa NM, A Selim L. Characterisation of COVID-19 pandemic in paediatric age group: A systematic review and meta-analysis. Journal of Clinical Virology. 2020; 128: 104395. DOI: https://doi. org/10.1016/j.jcv.2020.104395

65. Alvar J, Alves F, Bucheton B, Burrows L, Büscher P, Carrillo E, et al. Implications of asymptomatic infection for the natural history of selected parasitic tropical diseases. Seminars in Immunopathology. 2020; 42(3): 231-46. DOI: https://doi.org/10.1007/s00281-020-00796-y

66. Pan American Health Organization. Guidelines for the diagnosis and treatment of Chagas disease. Washington, DC; 2019. Available from: https://iris.paho.org/handle/10665.2/49653

67. Urbina JA. Ergosterol biosynthesis and drug development for Chagas disease. Memorias do Instituto Oswaldo Cruz. 2009; 104(Suppl1): 311-318. DOI: https://doi.org/10.1590/S007402762009000900041

68. Bern C, Montgomery SP, Herwaldt BL, Rassi A, Jr, Marin-Neto JA, Dantas RO, et al. Evaluation and treatment of Chagas disease in the United States: A systematic review. Jama. 2007; 298(18): 2171-2181. DOI: https://doi.org/10.1001/jama.298.18.2171

69. Sperandio da Silva GM, Mediano MFF, Hasslocher-Moreno AM, Holanda MTd, Sousa ASd, Sangenis LHC, et al. Benznidazole treatment safety: The Médecins Sans Frontières experience in a large cohort of Bolivian patients with Chagas' disease-Authors' response. Journal of Antimicrobial Chemotherapy. 2018; 73(4): 1115-1116. DOI: https://doi.org/10.1093/jac/dkx505

70. Pinazo MJ, Muñoz J, Posada E, López-Chejade P, Gállego M, Ayala E, et al. Tolerance of benznidazole in treatment of Chagas' disease in adults. Antimicrobial Agents and Chemotherapy. 2010; 54(11): 4896-4899. DOI: https://doi.org/10.1128/AAC.00537-10

71. Forsyth CJ, Hernandez S, Olmedo W, Abuhamidah A, Traina MI, Sanchez DR, et al. Safety profile of Nifurtimox for treatment of Chagas disease in the United States. Clinical Infectious Diseases. 2016; 63(8): 1056-1062. DOI: https://doi.org/10.1093/cid/ciw477 
72. Zheng Y-Y, Ma Y-T, Zhang J-Y, Xie X. COVID-19 and the cardiovascular system. Nature Reviews Cardiology. 2020; 17(5): 259-260. DOI: https://doi.org/10.1038/s41569-020-0360-5

73. Libby P. The heart in COVID-19: Primary target or secondary bystander? JACC: Basic to Translational Science. 2020; 5(5): 537-542. DOI: https://doi.org/10.1016/j.jacbts.2020.04.001

74. Shin J, Johnson JA. Pharmacogenetics of beta-blockers. Pharmacotherapy. 2007; 27(6): 874-887. DOI: https://doi.org/10.1592/phco.27.6.874

75. Salaroglio IC, Gazzano E, Abdullrahman A, Mungo E, Castella B, Abd-Elrahman G, et al. Increasing intratumor C/EBP- $\beta$ LIP and nitric oxide levels overcome resistance to doxorubicin in triple negative breast cancer. Journal of Experimental \& Clinical Cancer Research. 2018; 37(1): 286. DOI: https://doi.org/10.1186/s13046-018-0967-0

76. Zaidel EJ, Quintana FSW, Sosa Liprandi A, Mendoza I, Marquez MF, Nunez E, et al. Hidroxicloroquina. Mensajes desde la cardiología en tiempos de pandemia por coronavirus [Hydroxychloroquine: Cardiology's viewpoint in times of coronavirus pandemic]. Medicina (B Aires). 2020; 80(3): 271-274.

77. University of California-San Francisco. Interactions with Amiodarone and Antiretrovirals. 2019. Available from: http://arv.ucsf.edu/insite?page=ar-00-02\&post=8\&param $=116$.

78. Milazzo L, Cattaneo D, Cheli S, Ferraris L, Colella E, Clementi E, et al. ACE inhibitors and ribavirin-associated cough: A common undefined predisposing factor? European Journal of Clinical Pharmacology. 2013; 69(3): 743-745. DOI: https://doi.org/10.1007/s00228-012-1397-0

79. DrugBank. Ivermectin 2020 [updated June 30, 2020]. Available from: https://www.drugbank.ca/ drugs/DB00602.

80. DrugBank. Umifenovir 2020 [updated June 12, 2020]. Available from: https://www.drugbank.ca/ drugs/DB13609.

81. Chakraborty A, Tannenbaum S, Rordorf C, Lowe PJ, Floch D, Gram H, et al. Pharmacokinetic and pharmacodynamic properties of canakinumab, a human anti-interleukin- $1 \beta$ monoclonal antibody. Clinical Pharmacokinetics. 2012; 51(6): e1-e18. DOI: https://doi.org/10.2165/11599820-00000000000000

82. Novartis Pharmaceuticals Corporation. ILARIS (canakinumab) Full Prescribing Information 2012.

83. Patheon Italia. GAMIFANTTM (emapalumab-lzsg) injection, for intravenous use. 2018.

84. Janssen Biotech. SYLVANT. Full Prescribing Information 2014.

85. Campana C, Regazzi MB, Buggia I, Molinaro M. Clinically significant drug interactions with cyclosporin. An update. Clinical Pharmacokinetics. 1996; 30(2): 141-179. DOI: https://doi. org/10.2165/00003088-199630020-00004

86. Lill J, Bauer LA, Horn JR, Hansten PD. Cyclosporine-drug interactions and the influence of patient age. American Journal of Health-System Pharmacy. 2000; 57(17): 1579-1584. DOI: https://doi. org/10.1093/ajhp/57.17.1579

87. Pfizer Inc. RAPAMUNE. 2017.

88. Janssen Pharmaceutical Companies. PREZCOBIX (darunavir and cobicistat) tablets, for oral use. 2019.

89. Paranjpe I, Fuster V, Lala A, Russak AJ, Glicksberg BS, Levin MA, et al. Association of treatment dose anticoagulation with in-hospital survival among hospitalized patients with COVID-19. Journal of the American College of Cardiology. 2020; 76(1): 122-124. DOI: https://doi.org/10.1016/j. jacc.2020.05.001

90. Sousa AS, Xavier SS, Freitas GR, Hasslocher-Moreno A. Prevention strategies of cardioembolic ischemic stroke in Chagas' disease. Arquivos Brasileiros de Cardiologia. 2008; 91(5): 306-310. DOI: https://doi.org/10.1590/S0066-782X2008001700004

How to cite this article: Zaidel EJ, Forsyth CJ, Novick G, Marcus R, Ribeiro ALP, Pinazo MJ, Morillo CA, Echeverría LE, Shikanai-Yasuda MA, Buekens P, Perel P, Meymandi SK, Ralston K, Pinto F, Sosa-Estani S. COVID-19: Implications for People with Chagas Disease. Global Heart. 2020; 15(1): 69. DOI: https://doi.org/10.5334/gh.891

Submitted: 28 July $2020 \quad$ Accepted: 16 September $2020 \quad$ Published: 13 October 2020

Copyright: ( $) 2020$ The Author(s). This is an open-access article distributed under the terms of the Creative Commons Attribution 4.0 International License (CC-BY 4.0), which permits unrestricted use, distribution, and reproduction in any medium, provided the original author and source are credited. See http://creativecommons.org/licenses/by/4.0/. 